\title{
A INTERDEPENDÊNCIA DA PRÁTICA DOCENTE E A CONSTRUÇÃO DA HÉXIS CORPORAL DE PROFESSORES DE EDUCAÇÃO FÍSICA E SUAS CONSEQUÊNCIAS NA UNIDADE ESCOLAR
}

\author{
Fábio Tadeu REINA ${ }^{1}$, Luci Regina MUZZETI ${ }^{2}$, \\ Maria José ROMANATTO ${ }^{3}$, Flávia Baccin Fiorante INFORSATO ${ }^{4}$, \\ Maria Beatriz Loureiro de OLIVEIRA ${ }^{5}$
}

RESUMO: Este artigo mostra a interdependência existente entre a prática docente e a construção da héxis corporal de professores de Educação Física e as suas consequências na unidade escolar, condição essa verificada pelo itinerário social desses agentes sociais que ministram aulas em uma escola municipal de ensino fundamental, na cidade de Araraquara SP. Como pressuposto básico deste artigo, estabeleceu-se que a construção social da héxis corporal do professor de Educação Física é um processo em constante construção, pois é resultante de sua trajetória de vida com intervenções provenientes do contexto social em que vive. Nesse enfrentamento diário, o agente e/ou o seu grupo social tende a tornar visíveis os aspectos de dinamicidade e de permanência de sua ação. Em tal dinâmica, o agente e/ou o grupo a que pertence incorpora os elementos constituintes da realidade social e, a seu modo, exterioriza os conteúdos simbólicos interiorizados, compartilhando os traços de uma cultura comum que pode ser examinada através do conceito de habitus. A héxis, nesse sentido, é a dimensão que possibilita a internalização das conseqüências das práticas sociais e, também, a sua exteriorização corporal - através do modo de falar, gesticular, olhar, andar, sentar-se, manejar instrumentos, manter a postura da cabeça ou fazer caretas, cada vez mais associado a um tom de voz dos agentes sociais. As crianças são particularmente atentas, em todas as sociedades, a esses gestos e a essas posturas que caracterizam um adulto.

PALAVRAS-CHAVE: Héxis corporal. Habitus. Trajetória. Práticas culturais.

\section{Introdução}

Na Educação Física há uma prática fundamentalmente corporal, codificada, cuja lógica tende a ser apreendida em ação e corresponde a um modo de inculcar implícito, prático e coletivo. Essa prática é necessária e, ao mesmo tempo, relativamente pontual, porque ela é o

\footnotetext{
${ }^{1}$ Prefeitura Municipal de Araraquara. Secretaria Municipal de Esportes e Lazer de Araraquara - Ginásio de Esportes. Araraquara - SP - Brasil.14800000 - ftreina@ig.com.br

${ }^{2}$ UNESP - Universidade Estadual Paulista. Faculdade de Ciências e Letras - Departamento de Didática - PósGraduação em Educação Escolar. Araraquara - SP - Brasil. 14.800-901 - lucirm@fclar.unesp.br

${ }^{3}$ UNESP - Universidade Estadual Paulista. Faculdade de Ciências e Letras - Departamento de Ciências da Educação. Araraquara - SP - Brasil.14.800-901 - maze@fclar.unesp.br

${ }^{4}$ Doutoranda em Educação Escolar. UNESP - Universidade Estadual Paulista. Faculdade de Ciências e Letras. Pós -graduação em Educação Escolar. Araraquara - SP- Brasil. 14.800-901 - flafiorante@uol.com.br

${ }^{5}$ UNESP - Universidade Estadual Paulista. Faculdade de Ciências e Letras - Departamento de Psicologia da Educação. Araraquara - SP - Brasil. - 14.800-901 - bia@fclar.unesp.br.
} 
produto da relação dialética entre uma situação e um habitus. Segundo Bourdieu (apud DURAND, 1979), o habitus é entendido como um sistema de disposições duráveis e transponíveis que, integrando todas as experiências passadas, funciona, a todo momento, como uma matriz de percepções, de apreciações e de ações, e torna possível a realização de tarefas infinitamente diferenciadas, graças às transferências analógicas de esquemas, que permitem resolver os problemas da mesma forma, e às correções incessantes dos resultados obtidos, dialeticamente produzidas por esses resultados. De acordo com o depoimento de professores de Educação Física, observa-se que:

[...] a Educação Física é fundamental para as crianças, elas precisam gostar de trabalhar seu corpo. Hoje em dia com televisão, vídeo game isso não acontece então talvez à única oportunidade que elas têm de se soltar, de fazer seu corpo trabalhar seja na aula de Educação Física, com isso elas praticando o esporte, fazendo uma brincadeira, vai fazer com que não fiquem paradas, e no futuro sejam adultos ativos e não sedentários. (Depoimento prof. C - sic).

O esporte faz parte das práticas culturais e pode ser praticado por agentes de um mesmo grupo ou de uma sociedade diferenciada, de diferentes camadas sociais. Essas práticas culturais são dotadas de um sentido objetivo, ao mesmo tempo unitário e sistemático, que tende a transcender às intenções subjetivas e aos projetos conscientes, individuais ou coletivos. Observa-se na fala de um professor que há mais facilidade para se ensinar os fundamentos das modalidades esportivas: “[...] eu tenho mais facilidade em ensinar os fundamentos das modalidades esportivas, por conta que eu executei muito eles e isso me trás uma segurança muito grande.” (Depoimento prof. D - sic).

A transmissão dos conteúdos da disciplina efetua-se de forma gestual, visual e mimética, sob o valor de uma manipulação regulada pelo corpo. Essa regulação ocorre por causa das exigências motoras culturalmente regradas que o professor apresenta durante a execução correta de um gesto motor, de qualquer habilidade motora (básica ou especializada), como observado nos depoimentos: “[...] a maioria dos exercícios eu mesmo faço, se são simples de executar apenas peço para eles mesmos fazerem, mais se são difíceis de realizar eu mesmo faço para que ao me virem realizar eles também realizem” (Depoimento prof. B - sic) e “[...] eu demonstro os exercícios quando necessário, sempre falo do uniforme, do tênis no pé, da bermuda ou da calça adequada para a prática dos conteúdos da disciplina de Educação Física.” (Depoimento prof. E - sic). Portanto, todas essas disposições inculcadas pelos alunos, diante dessa ação motora prática, planejada pelo professor, conduzem à soma do saber coletivamente enraizado e exteriorizado pelos professores a cada patamar de sua trajetória de 
vida. Nesse sentido, as experiências vividas pelos professores se integram na unidade de uma biografia sistemática, que se organiza a partir da situação originária de classe, experimentada em um determinado tipo de estrutura familiar. Observe-se os seguintes depoimentos de professores:

Eu morava numa rua sem saída, nós tínhamos uma área nesta rua que era destinada a construção de uma praça, mas acabou nem sendo construída, nós ficávamos neste espaço brincando de: esconde-esconde; balança caixão; bolinha de gude; pular corda; pular elástico; tinha muitas brincadeiras de bate-palma; de cantigas de roda; brincávamos nós as meninas e os meninos;andávamos de bicicleta.

Fui muito a eventos esportivos, principalmente eu assisti a muitas São Silvestre [corrida de pedestrianismo realizada na cidade de São Paulo, na passagem do ano dia 31/12], e na época esta corrida acontecia à meia-noite do dia 31 de Dezembro, para nós era um evento familiar, nós gostávamos de aplaudir. [...] Outra coisa que eu me lembro muito bem, eram os campeonatos de futebol que meu pai freqüentava aos finais de semana com seu grupo de amigos, nesses campeonatos nós íamos junto, até hoje eu gosto de futebol por conta disto. (Depoimento prof. A- sic).

Brincadeiras só as proporcionadas pelo clube que frequentávamos desde pequenininhas. [...] Todo funcionário da usina frequentava o mesmo clube, e nós desde pequenininhas frequentávamos este clube. [...] Eventos esportivos, só os realizados na usina pelo pessoal que lá morava, todo ano tinha um evento que envolvia todos os funcionários e nós íamos. (Depoimento prof. B - sic).

Portanto, os itinerários de vida percorridos por esses professores, com gênese no seio familiar, determinam as primeiras experiências motoras herdadas na socialização primária, adquirida na família e que, segundo Bourdieu (apud DURAND, 1979), constituem o habitus do agente social (neste caso, professores de Educação Física). Para Bourdieu (1983, p.60-61), o habitus, sendo um sistema de disposições duráveis, é apropriado pelos agentes por meio do processo de socialização vivenciado por eles primeiramente no interior da família e funciona como "estruturas estruturadas predispostas a funcionarem como estruturas estruturantes". Ou seja, o habitus, adquirido nas primeiras experiências vivenciadas no contexto familiar por meio da educação depositada em cada agente social pela família, constituir-se-á como esquema de percepção e de apreensão de todas as experiências posteriores, principalmente as experiências vivenciadas no interior da escola, pois:

[...] a escola uma instância oficialmente incumbida de assegurar a transmissão dos instrumentos de apropriação da cultura dominante que não se julga obrigada a transmitir metodicamente os instrumentos indispensáveis ao bom êxito de sua tarefa de transmissão, está destinada a transformar-se 
em monopólio das classes sociais capazes de transmitir por seus próprios meios, quer dizer, mediante a ação da educação contínua e difusa e implícita, que se exercem nas famílias cultivadas, os instrumentos necessários para, assegurar a essas classes o monopólio dos instrumentos de apropriação da cultura dominante e por essa via, o monopólio desta cultura. (BOURDIEU, 1974, p.307).

Nesse sentido, as disposições herdadas no seio familiar, e reestruturadas pela escola, serão os condicionantes que caracterizarão o agente pelo seu modo de andar, falar, vestir-se, escolher uma prática esportiva, se aproximar dos conteúdos específicos da área da Educação Física, enfim, sua construção social da héxis corporal, ou seja, segundo Bourdieu (1983), "seu habitus feito corpo":

Olha eu freqüentei uma escola Municipal de dança em São Paulo, e nós tínhamos apresentações semestrais, tínhamos os próprios recitais da escola Municipal de dança, além disso, havia as apresentações dos colegas que faziam parte dessa escola, então os nossos professores de dança levavam a gente para ir assistir no teatro. [...] Quando eu morava em São Paulo, os primeiros anos eu estudei em uma escola de tempo integral, então nós tínhamos muitas atividades esportivas, não somente esportes, mas várias outras atividades da área de Educação Física, eu gostava muito de GRD (ginástica rítmica desportiva) e ginástica olímpica. (Depoimento prof. A sic).

Dessa maneira, os alunos tendem a aprender as habilidades motoras desses conteúdos da área da Educação Física preconizada pelos PCNs (Parâmetros Curriculares Nacionais) e desenvolvidos na escola, por meio da héxis corporal desses professores, ou seja, pela maneira como os professores demonstram os exercícios, como eles realizam tais demonstrações, vendo seus gestos motores, imitando sua sequencialidade de movimentos, percebendo suas respostas ao movimento proposto, tudo isso consciente ou inconsciente sem a intenção muitas vezes explícita do professor para que isso ocorra.

Assim, de acordo com Bourdieu (1983), podemos dizer que a visão de mundo de um professor de Educação Física, sua maneira de ganhar sua rentabilidade financeira, sua ascensão social, seu tempo ou seu corpo, seu uso da linguagem e suas escolhas indumentárias, estão inteiramente presentes em sua práxis em sala de aula e quadra, pois, para se efetivar as necessidades e as exigências da profissão docente, planejar e organizar os conteúdos e para que haja um aprendizado correto por parte dos alunos, precisa-se ter um cuidado especial com sua héxis corporal: 
Não deixo as meninas fazer aulas de Educação Física de shorts minúsculos, muito menos vir de bustiê, elas devem saber que existem roupas apropriadas para determinadas coisas, calçados apropriados para fazer aulas de Educação Física e para ir ao shopping, eles têm que saber que tipos de roupa devem usar sim. [...] Falo bastante com eles principalmente dessa moda dos chicletes e pirulito na boca. Eles chupam de quatro a seis pirulitos por dia, então eu informo quantas calorias têm isso tudo, o quanto de atividade física será necessário para gastar essas calorias. E que um dia mais velho poderá ficar gordo. (Depoimento prof. C - sic).

Se os alunos imitam, consciente ou inconsciente, o professor, deduz-se que o professor deve, em suas aulas, trajar um vestuário apropriado para a realização da prática diária (calça de ginástica, shorts ou bermuda, tênis, camiseta). Além disso, sua fala deve ter ser um tom suficiente para que todos possam ouvi-lo bem, suas expressões faciais devem proporcionar alegria e devem motivar os alunos para a realização das atividades propostas e as escolhas das atividades devem favorecer a inclusão dos alunos no interior da escola.

Com isso, essas particularidades exigidas na construção da héxis corporal poderão proporcionar-lhes condições de aferir que o desenvolvimento da disciplina de Educação Física e a prática de seus conteúdos, por parte dos alunos, estão intrinsecamente relacionados à maneira com que suas hexis corporais de professores de Educação Física foram construídas ao longo de suas experiências de vida, originadas no seio familiar e reestruturadas por outras agências socializadoras, como escolas, faculdades, clubes e igrejas.

Em relação à proximidade dos conhecimentos adquiridos com os conteúdos desenvolvidos na Faculdade, depõem os professores:

As matérias biológicas são as mais difíceis: anatomia, fisiologia e cinesiologia, elas são disciplinas que exigem um pouco mais de você, mas elas são tão aplicáveis, são conteúdos tão aplicáveis na nossa área que acaba se tornando um conteúdo fácil, eu gosto muito dessas matérias também.(Depoimento prof. A - sic).

Tive muitas dificuldades com Anatomia, Fisiologia e Cinesiologia, pois achava essas disciplinas difíceis, tinha que estudar os ligamentos, funções dos órgãos e músculos. Sinto muita falta dessas disciplinas no meu dia a dia, deveria ter estudado mais, porque saberia entender mais sobre um treinamento seus efeitos, quando o aluno se machuca o que realmente ocorreu, qual o músculo que ele machucou e quais as condições fisiológicas que ele se encontra num treinamento. (Depoimento prof. B - sic).

A minha maior dificuldade foi com a disciplina de anatomia, porque no início nós não tínhamos laboratório na Faculdade, ficou uma disciplina muito teórica. [...] Sempre tive um bom rendimento nas disciplinas voltadas 
às modalidades esportivas, porque quando criança, adolescente e até na fase adulta tive muito contato com elas. (Depoimento prof. D - sic).

Nas palavras de Bourdieu (1990, p.89):

As condições materiais de existência próprias de um tipo particular de meio, ou seja, próprias de um determinado grupo social ou fração de classe e sua objetivação no contexto familiar, constituem, segundo ele, uma mediação fundamental na produção das estruturas do habitus, que gera a exteriorização dessas disposições duráveis e transponívies que exprime sob a forma de preferências sistemáticas, as necessidades objetivas das quais ele é o produto.

Com isso, o habitus, sendo um operador prático dessas preferências, determina o estilo de vida de cada agente social. Esse estilo de vida, que caracteriza particularmente cada agente social e é determinado pelas condições materiais de existência, vai se manifestar nas distinções e nos gostos, nas escolhas dos esportes e dos jogos, ou seja, do desenvolvimento dos conteúdos da área de Educação Física no âmbito escolar: “[...] eu gosto de todos os esportes, eu gosto de jogos, de recreação, lazer, brincadeiras, lutas, ginástica, tanto é, que era difícil eu escolher estágio, eu queria aprender sempre tudo [...]” (Depoimento prof. A - sic), “[...] nas séries iniciais do ensino fundamental eu trabalho brincadeiras, mas nas demais séries eu trabalho o esporte, divido um esporte por bimestre [...]” (Depoimento prof. B - sic), “[...] eu trabalho coordenação, esportes, ministro aulas de dama, xadrez, jogos cooperativos, ginástica, recreação, ou seja, um pouco de tudo [...]” (Depoimento prof. C - sic) e “[...] eu gosto de trabalhar com atletismo, me chama a atenção, as regras que mudam, eu sempre estou a par delas, eu gosto de atletismo por assistir bastante, por ir no ginásio da pista, levá-los à competir o atletismo fez com que eu gostasse bastante da modalidade.” (Depoimento prof. D sic).

Além dessa condição específica do gosto e da escolha por um determinado conteúdo para ser consumido, esse estilo próprio de vida leva também à distinção, na lógica específica de cada um dos subespaços simbólicos, nas vestimentas, na linguagem, ou seja, na héxis corporal, como exemplificam os depoimentos:

Quanto aos valores que eu transmito, ou melhor, tento passar para eles de comportamento, de família de como eles vão se comportar lá fora, eu estou sempre sentando com eles e conversando sobre isso, converso principalmente com os alunos do nono ano do ensino fundamental que são adolescentes de quatorze, quinze anos de idade. Muitas vezes eles não querem ter aula prática querem ficar conversando comigo sobre a minha infância, aí eu conto para eles como ela foi, que eu tive uma criação religiosa, essa educação religiosa eu tento transmitir a eles, o valor que tem 
que ser dado ao corpo. Falo desse corpo, que nós temos que cuidar, eu sempre trago coisas minhas do meu passado, eles sempre escutam, alguns torcem o nariz. Com isso percebo que algumas vezes eu alcanço resultados bons com essas conversas e assim com a minha vivencia e com $\mathrm{s}$ valores que sempre acreditei serem corretos. (Depoimento prof. B - sic).

Eu adoro dar aulas no CAIC do Vale do Sol, não gostaria de sair daqui nunca, são crianças ótimas, tudo o que você propõe eles fazem. Eu acho que eles gostam da minha aula sim, porque mesmo alunos que eu não dou mais aula esse ano, vem me abraçam, falam que tem saudades de mim, tem saudades da minha aula. [...] Toda a mudança de comportamento que observei dos meus alunos, deveu-se ao fato do convívio da amizade, da conversa que temos e do carinho, porque eles nos procuram para responder dúvidas ou dificuldades que eles tenham, eles conversam coisas da vida particular, assuntos de família, namoro, pedem conselhos. [...] Eu me sinto valorizada, respeitada e prestigiada pelos alunos, pela direção da escola e principalmente pelos pais que agradecem por ter feito algo pelos seus filhos. (Depoimento prof. C - sic).

"É uma satisfação muito grande, nós somos uma escola de periferia, as crianças têm poucas opções, esta situação torna o trabalho agradável, porque os alunos se sentem realizados com a atividade, aqui nós temos um reconhecimento muito grande das crianças e de seus pais”. (Depoimento prof. D - sic)

Portanto, a construção dessa héxis corporal, vislumbrada com essas trajetórias de vida, culmina com a prática escolar que esses professores realizam com a Educação Física no interior da escola. Dotada de uma eficácia simbólica, a héxis corporal é responsável pelo status do professor, pelo seu sucesso entre os alunos, pais e direção da escola e pelo papel educativo do professor desempenhado na escola, pelo qual os professores se autoavaliam.

Com essa perspectiva, é possível entender que a lógica da prática desses professores entrevistados tem como epicentro o habitus de cada um, que se reestrutura ao longo do itinerário de suas vidas. E é justamente por levar em consideração essa condição inscrita em seus corpos que se pode perceber que a prática desses professores muitas vezes ratifica os paradigmas que outrora foram legitimados pela escola como, por exemplo, a esportivização como condição hegemônica de conteúdo a ser desenvolvido na escola.

\section{Metodologia}

Neste estudo, foram entrevistados cinco professores de Educação Física de uma escola municipal localizada na região periférica da cidade de Araraquara/SP, sendo quatro professoras e um professor. Há semelhanças em suas respostas, pois, segundo Bourdieu, 
agentes sociais originários de uma mesma fração de classe, que têm as mesmas condições materiais de existência e são sujeitos às mesmas ações práticas, tendem a ter a homogeneização de seus habitus, portanto, a regularidade das disposições aqui encontradas leva a crer que os resultados desta pesquisa se ratificam e se tornam relevantes em outras unidades de ensino que possuem características semelhantes.

Por essa pesquisa ter sido realizada em uma escola municipal, onde as aulas de Educação Física são efetuadas fora do período regular de aulas (apenas os alunos do Ciclo I do Ensino Fundamental têm aulas de Educação Física no mesmo período das aulas das demais disciplinas do currículo escolar), pensou-se que haveria preferência na escolha de turmas por parte dos professores, preferindo o professor dar aulas para os meninos e as professoras para as meninas, mas isso não ocorreu. Encontrou-se professor e professoras, aleatoriamente, com turmas masculinas, femininas e mistas. Portanto, percebeu-se que nas eventuais escolhas dos professores não é significativa a questão de gênero dos alunos.

Como mencionado anteriormente, a escola municipal está localizada em um bairro periférico da cidade, e, segundo uma pesquisa realizada pela direção da escola para apontar a fração de classe dos alunos, chegou-se à conclusão de que são alunos provenientes das camadas populares. De acordo com o referencial teórico sociológico de Pierre Bourdieu, alunos provenientes das camadas populares possuem baixo patrimônio herdado do seio familiar, ou seja, esses alunos possuem um capital econômico, cultural e social prejudicados, alicerçado pelas condições materiais de existência.

Diferentemente da fração de classe dos alunos, todos os professores de Educação Física da escola são provenientes da classe média (segundo seus depoimentos), fato que nos leva a inferir que suas disposições, e seus patrimônios herdados do seio familiar, são melhores em termos de capital econômico, cultural e social do que a realidade dos seus alunos.

Além dessa dinâmica instaurada pela escola com a Educação Física, os professores são, na maioria, pós-graduados. Os materiais utilizados nas aulas são comprados em grande volume, além de a prática ter o favorecimento de espaços físicos proporcionados pela arquitetura da escola.

Para realizar a pesquisa, fez-se primeiro contato com a direção da escola, para respeitar hierarquicamente a estrutura e o funcionamento da instituição escolar, visando a facilitar a entrada na escola e a ultrapassar possíveis obstáculos por parte dos professores em relação à pesquisa. Conversou-se pessoalmente com a diretora da escola, que se mostrou receptiva e permitiu a realização do trabalho, sem ao menos discutir com profundidade o projeto a ser desenvolvido. A tarefa seguinte foi procurar os cinco professores da escola, para 
marcarmos as entrevistas. Com o quadro de horários dos professores e com os horários do HTPC (horário de trabalho pedagógico coletivo), fornecidos pela secretaria da escola, em mãos, conversou-se diretamente com todos os professores. Esses, solícitos, predispuseram-se a responder as questões das entrevistas, realizadas na escola em horários por eles determinados, que não atrapalharam o andamento normal de suas atividades docentes e nem particulares.

Vale destacar a maneira como esses professores são identificados, pois o professor de Educação Física se apresenta de maneira diferente dos outros funcionários da escola, tanto por suas vestimentas e modo de ocupar os espaços físicos para suas aulas, como por seus horários. Só essas questões já apontam caminhos importantes para se pensar na construção da héxis corporal desse profissional e da sua relação no âmbito escolar.

Em relação à vestimenta, na maioria das vezes foram encontrados professores trajando agasalhos esportivos e tênis. Suas atitudes comportamentais, de um modo geral, apontam para professores extrovertidos, alegres, simpáticos, muito falantes e preocupados com suas estéticas corporais.

Observou-se, também, uma aproximação maior dos alunos da escola com os professores de Educação Física do que com os professores das outras disciplinas. Essa aproximação foi percebida pelo tipo de cumprimento, pelas expressões faciais que os alunos manifestavam ao encontrá-los e, também, pelo carinho e pela atitude tanto paternal como maternal dos professores para com seus alunos.

A identificação do professor de Educação Física também se dá pelo seu horário, que, como mencionado anteriormente, é diferente do horário seguido pelos demais professores da escola. Em relação aos locais em que esses professores ficam quando não estão dando aulas (nas quadras e nos espaços físicos designados para a prática das aulas), constatou-se também diferenças em relação aos demais professores da escola, pois eles geralmente ficam na sala de materiais esportivos ou em uma sala reservada perto da quadra. Dificilmente eles vão à sala dos professores, embora mantenham relacionamento muito amistoso com os demais professores da escola.

Os cinco professores entrevistados, como já dito, quatro professoras e um professor, com faixa etária entre 30 e 45 anos, são formados em Educação Física em faculdades do Estado de São Paulo, nas décadas de 1980 e 1990, localizadas em cidades próximas à cidade de Araraquara e pertencentes à mesma região do Estado. Para preservar suas identidades, optou-se por nominá-los com letras do alfabeto. 


\section{Considerações finais}

Na Educação Física, há uma prática essencialmente corporal e codificada, cuja lógica só pode ser apreendida em ação. Dessa maneira, corresponde a um modo de inculcar implícito, prático e coletivo. A transmissão dos conteúdos da disciplina efetua-se de forma gestual, visual e mimética, sob a operacionalidade de uma manipulação regulada do corpo.

Essa operacionalidade se deve às exigências regradas do professor que, por meio de sua héxis corporal, dá o tom de especificidade na aprendizagem dos conteúdos específicos da disciplina de Educação Física no âmbito escolar.

Portanto, neste artigo, fica claro que a formação docente e seu envolvimento com o ensino é puramente social e plural, ou seja, oriundo de agências socializadoras das quais esse professor teve contato durante a sua trajetória de vida, tais como a família, a escola e a universidade, entre outras.

Nessa direção, este artigo evidencia, mesmo que subliminarmente, que, para que se possa considerar a identidade social do professor, seus saberes, suas relações com os conteúdos da disciplina de Educação Física e suas práticas no interior da escola, deve-se levar em consideração a sua trajetória de vida e as suas experiências vivenciadas antes de entrar na graduação e não unicamente os conhecimentos adquiridos nesse nível de educação.

O contato com as experiências, principalmente voltadas ao esporte, estimula e desenvolve a expressão corporal. Paralelo a isso, ficou transparente, no desenrolar da pesquisa que originou este artigo, que se tornar professor de Educação Física tinha um alto patamar de exigência em termos de conhecimento e que os professores dispunham em suas aulas da chamada linguagem corporal.

Embora todos os professores mantenham uma aproximação em relação a essa linguagem, é fato que o curso de Educação Física desenvolvia, na sua maioria, a capacidade especifica da técnica corporal das habilidades motoras voltadas aos esportes, com exigência de rigor e correção, estabelecendo um crescimento unilateral em relação à linguagem corporal já dominada por esses professores, reestruturando, maximizando, assim, o seu capital esportivo.

Assim, este artigo sinaliza que outras práticas pedagógicas são importantes na consolidação dessa héxis corporal, como por exemplo, conteúdos de dança, ginástica, lutas, recreação, jogos, como também, a ida a eventos esportivos, congressos, palestras, cursos de aperfeiçoamento e capacitação e continuidade em estudos de pós-graduação. 
Pode-se observar também que a escola, como força hegemonicamente reestruturadora de habitus, transmite conhecimentos e condutas que são utilizadas na mudança de comportamentos e na aceitação de valores.

Por fim, o artigo explicita que ser professor de Educação Física, nessa escola Municipal, é ter uma valorização e aceitação muito grande no espaço escolar e que essa realidade se torna motivo de estímulo para que os professores continuem a acreditar que a Educação Física é muito importante para a formação da identidade social dos alunos.

\section{THE INTERDEPENDENCE OF THE TEACHING PRACTICE AND THE CONSTRUCTION OF THE PHYSICAL EDUCATION TEACHER'S BODILY HEXIS AND HER CONSEQUENCES IN THE SCHOLAR UNITY}

ABSTRACT: This article shows the interdependence existing between the teaching practice and the construction of the physical education teacher's bodily hexis and it consequences in the scholar unity. This condition is verified by the social itinerary of these social agents who minister classes in a municipal school of fundamental education at Araraquara city - SP. As basic presuppose of this article, was established that the construction of de physical education teacher's bodily hexis is a process in constantly construction, because is resulting of his life trajectory with interventions from his social context, where he lives. In this daily relation, the agent and/or his social group tend to turn visible the dynamical aspects and the enduring character of his actions. In that dynamic, the agent and/or his social group embody the elements constituents of the social reality, and, in your way, express yours internal symbolic contents, to sharing the traces of a common culture, that can be examined by de habitus conceit. A hexis, in this sense, is the dimension who makes possible the process of internalize the consequences of the social practices and, too, his corporal expresses - by the way of to talk, to gesticulate, to look, to walk, to sit, to handle instruments, to keep the head or to grimace, each time more associated to social agents' voice tone. The children are particularly attentive, in all societies, to these signs and these postures who characterize one adult.

KEYWORDS: Bodily hexis. Habitus. Path. Cultural practices.

\section{REFERÊNCIAS}

BOURDIEU, P. Coisas ditas. Tradução de Cássia R. da Silveira e Denise Moreno Pegorim. São Paulo: Brasiliense, 1990.

Pierre Bourdieu: sociologia. Organizado por R. Ortiz. São Paulo: Ática, 1983. (Grandes Cientistas Sociais). 
A economia das trocas simbólicas. Introdução, organização e seleção Sergio Miceli. Tradução de Sergio Miceli de Almeida Prado, Sonia Miceli e Wilson Campos Vieira. São Paulo: Perspectivas, 1974.

DURAND, J. C. G. (Org). Educação e hegemonia de classe: as funções ideológicas da escola. Tradução de Maria Alice Machado de Gouveia. Rio de Janeiro: Zahar, 1979.

\section{BIBLIOGRAFIA CONSULTADA}

BOURDIEU, P. A dominação masculina. Tradução de Maria Helena Kuhner. Rio de Janeiro: Bertrand do Brasil, 1999.

A escola conservadora: as desigualdades frente à escola e à cultura. In:

NOGUEIRA, M. A.; CATANI. A. (Org). Escritos de educação. Petrópolis, Vozes, 1998. p.93-104.

A escola conservadora: as desigualdades frente à escola e a cultura. Tradução de Aparecida Joly Gouveia. Educação em Revista, Belo Horizonte, n.10, p.3-15, dez. 1989.

BOURDIEU, P.; PASSERON J. C. A reprodução: elementos para uma teoria do sistema de ensino. Tradução de Reynaldo Bairão. Rio de Janeiro: F. Alves, 1975. 